\title{
Effect of the COVID-19 pandemic at secondary power distribution
}

\author{
Sebastián García ${ }^{1 *}$, Antonio Parejo ${ }^{1}$, Enrique Personal ${ }^{1}$, Juan Ignacio Guerrero ${ }^{1}$, Félix Biscarri ${ }^{1}$, Carlos León ${ }^{1}$ \\ 1 Department of Electronic Technology, Escuela Politécnica Superior, Universidad de Sevilla, 41011 Sevilla, Spain \\ * Author to whom correspondence should be addressed (sgarcia15@us.es).
}

\section{ABSTRACT}

The COVID-19 pandemic has caused problems all around the world. To control the spread of the virus, some governments have imposed restrictions on the mobility of their citizens. Specifically, in Spain, from the months of March to May, lockdown was imposed. The effect of these actions is reflected not only on epidemiological data, but also on the behavior of the population, and therefore, some of their sectors. One of these sectors is the energy consumption. In this sense, this paper studies the impact that the COVID-19 pandemic has had on energy consumption using the data from the Smart Meters of the secondary distribution network at low-voltage. This approach has de advantage that is not only able to obtain the impact at aggregated level but is also able to obtain the impact on smaller groups at customer level. The results show an increase in energy consumption on residential customers in contrast with a remarkable reduction on non-residential customers. In the case of non-residential customers, different consumption patterns have been found during the pandemic. These consumption patterns are highly correlated with the restrictions imposed to control de spread of the pandemic.

Keywords: Demand Analysis, Data Analysis, Impact Evaluation, Smart Grid.

\section{NOMENCLATURE}

\section{Abbreviations}

$\begin{array}{ll}\text { SM } & \text { Smart Meters } \\ \text { AMI } & \text { Advanced Metering Infrastructure } \\ \text { DSO } & \text { Distribution System Operator } \\ \text { DCU } & \text { Data Concentrator Units } \\ \text { PLC } & \text { Power Line Communications }\end{array}$

NACE

Statistical Classification of Economic

Activities in the European

Community (French acronym)

\section{INTRODUCTION}

The SARS-CoV-2, which causes the COVID-19, has caused problems all around the world since its discovery in late 2019 in Wuhan (China). The quick spread of the virus has caused the governments of the affected countries to take actions to stop its advance. Mobility restrictions and lockdowns have been taking place in many countries, firstly in Asia and later in Europe and America. These measures have had an important impact, not only on epidemiological data, but also on society's behaviors and economies. This impact has been reflected on the $\mathrm{CO}_{2}$ emissions and the energy consumption.

In this sense, some authors have evaluated the impact that the COVID-19 has had over environmental data. In particular, [1-3] have evaluated the impact on $\mathrm{CO}_{2}$ emissions globally and also on China and the United States, obtaining similar results of reductions of $\mathrm{CO}_{2}$ between $15 \%$ to $20 \%$.

One sector in which the COVID-19 has had an important impact is the energy consumption. Due to the restrictions imposed to control the spread of the virus, the energy consumption patterns have changed during mobility restrictions and lockdowns as well as the $\mathrm{CO}_{2}$. In this sense, some papers have been publishing evaluating this impact [4-6]. In these papers, aggregated analysis at country or region level are performed obtaining a noticeable reduction in the energy consumption. Based on these changes on the consumption patterns, in [7] the authors proposed recommendations for the grid operation during the pandemic time.

Selection and peer-review under responsibility of the scientific committee of the 12th Int. Conf. on Applied Energy (ICAE2020). 
It is clear that the COVID-19 has had an impact on energy consumption, but this impact has been evaluated at an aggregated level. In this context, this paper studies the impact that the COVID-19 has had on lower levels of the grid: at secondary power distribution (low-voltage). This approach has the advantage that the impact can be evaluated with more detail, obtaining how the COVID-19 pandemic is affecting to specific groups of customers.

Thus, this paper is organized as follows: Section 2 briefly describes the Advanced Metering Infrastructure (AMI) at secondary distribution network. Consumption patterns regarding the COVID-19 restrictions using Smart Meters (SM) data are presented in Section 3. Finally, the conclusions are presented in Section 4.

\section{ADVANCED METERING INFRASTRUCTURE AT SECONDARY DISTRIBUTION}

Traditionally, the secondary distribution network, in contrast with primary distribution and transmission, has had a low level of instrumentation. But, in the recent years, thanks to the deployment of the AMI with millions of SM, the secondary distribution network has increased its monitoring capabilities [8].

The AMI is basically composed by two devices: SM and Data Concentrators Units (DCU). SM are installed in the supply points at customer level while DCU are installed at the secondary distribution substations. DCUs can remotely manage the SM through Power Line Communications (PLC). This structure can be seen in the Figure 1.

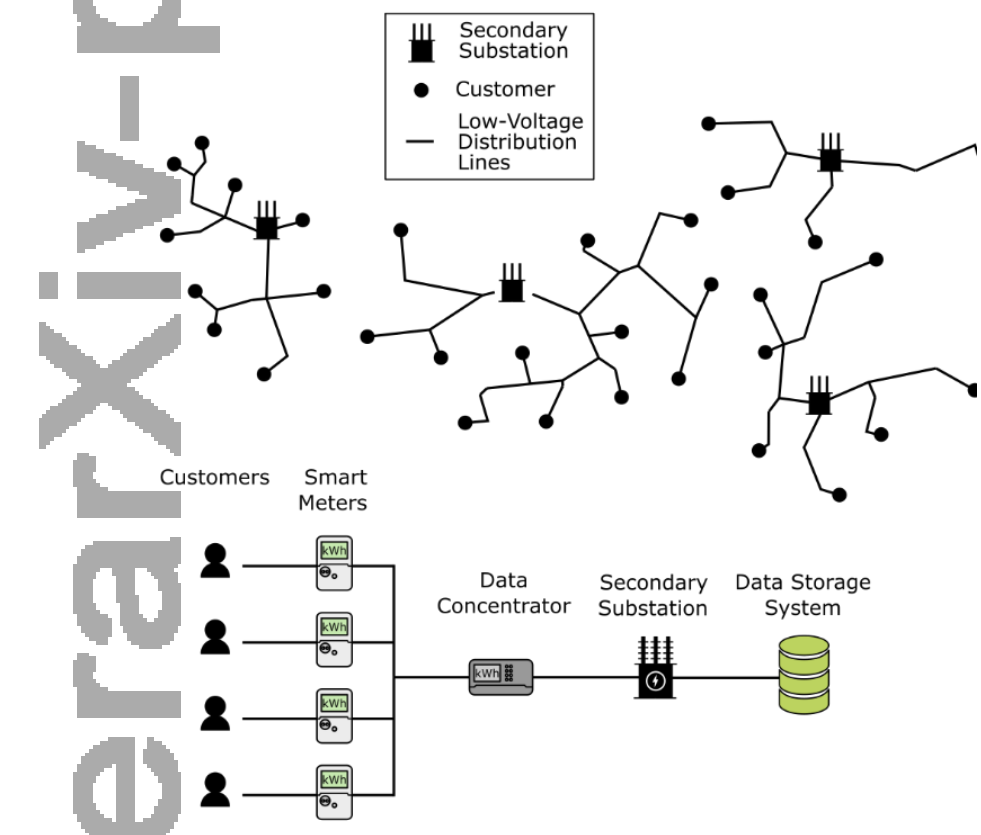

Fig 1. Schema of the AMI system at secondary distribution network.
With the AMI, Distribution System Operators (DSOs) are able to obtain consumption measurement as well as other electric parameters from SM through the DCU. Additionally, DSOs can remotely manage SM to set customer's configuration (tariff, power limits, etc.). In this sense, the analysis of the huge volume of data generated by the AMI can help on the designing of a safer, better and more effective power grid [9]. In addition, high-resolution data from SM provide rich information on the electricity consumption behaviors and lifestyles of the consumers [10].

Thus, with this infrastructure and the data that is generating, the impact of COVID-19 over the secondary distribution network at customer level can be evaluated.

Thanks to the collaboration with the Medina Garvey Company, a DSO from Andalusia (Spain), the data from its AMI are available. The town of Manzanilla has 14 secondary distribution substations with a total of 1426 SM deployed over the grid. In this sense, the data from Manzanilla (a town from Andalucía, Spain) has been used to evaluate how the COVID-19 has affected on lowvoltage customers during the lockdown of the months from March to May and the successive restrictions during the reopening after the lockdown.

\section{IMPACT EVALUATION}

Firstly, it is important to review some relevant dates in the course of the pandemic in Spain. On March $14^{\text {th }}$, with the exponential rising of the cases, the lockdown was imposed, people had to stay home and non-essential business were not allowed to open. Later, when the number of cases dropped, on May $11^{\text {th }}$ the strict lockdown was softened allowing businesses to open gradually and also allowing the mobility of the population (also gradually) until June $21^{\text {st }}$ when all restrictions were removed. Therefore, four stages can be found: a state before the COVID-19 restrictions, a strict lockdown, a softened lockdown with a reopening period and the full reopening when all the restrictions were removed.

As it was said, the data coming from the SMs deployed in the town of Manzanilla will be used. Figure 2 shows the aggregated energy consumption of all the SMs of the town. The background colors reflect the above described stages. The green background reflects periods with no restrictions, the red background reflects the strict lockdown and the yellow reflects the softened 
lockdown with the gradually reopening period. This color model will be used throughout the paper. In addition, the black line represents the consumption during 2020 and the red line represent the average consumption during the two previous years in the same period.

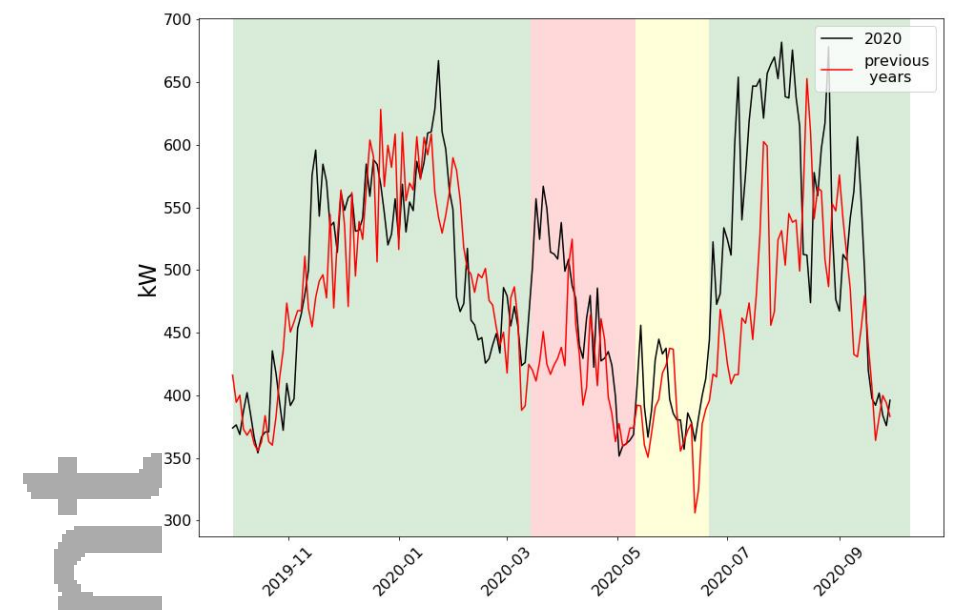

Fig 2. Aggregated consumption of the town of Manzanilla from October 2019 to October 2020 compared with the consumption at the same period of the previous years.

Seeing the aggregated consumption of the whole town, it is possible to appreciate a certain seasonality along the year having higher consumptions during winter and summer in contrast with a lower consumption during spring and autumn. However, during the strict lockdown (red stripe) a noticeable increment in the consumption can be observed in contrast with the average consumption of the previous years in the same period.

\subsection{Comparison between businesses and households}

Using the metadata associated to each SM, residential and non-residential low-voltage customers can be evaluated separately thanks to the NACE code. The NACE code is a European classification of economic activities that every customer has. Thus, using this code, customers can be split into residential and nonresidential. Figure 3 shows the consumption of residential customers while Figure 4 shows the consumption of non-residential customers.

From these figures, it can be seen that the behavior pattern of residential customers is pretty similar to the behavior of the aggregated consumption of all the customers of the town. This can be explained by the fact that just a $7 \%$ of SMs are associated to non-residential customers. Therefore, the aggregated consumption of the town is biased by residential customers.

However, the consumption profile of non-residential customers is quite different from residential customers showing a remarkable decrease in the consumption during the strict lockdown period. This behavior is consistent with the restrictions imposed to control the spread of the virus since most of business had to remain closed during this period.

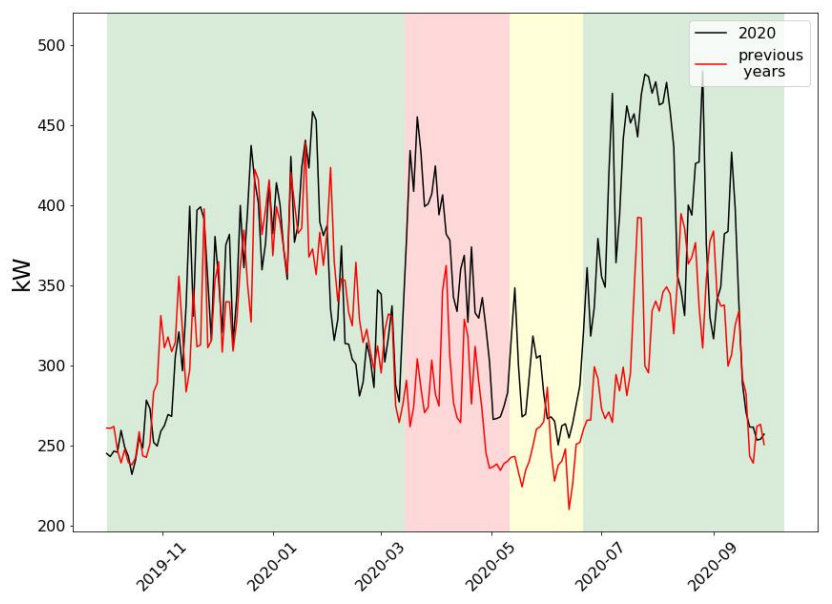

Fig 3. Aggregated consumption of residential customers from October 2019 to October 2020 compared with the consumption at the same period of the previous years.

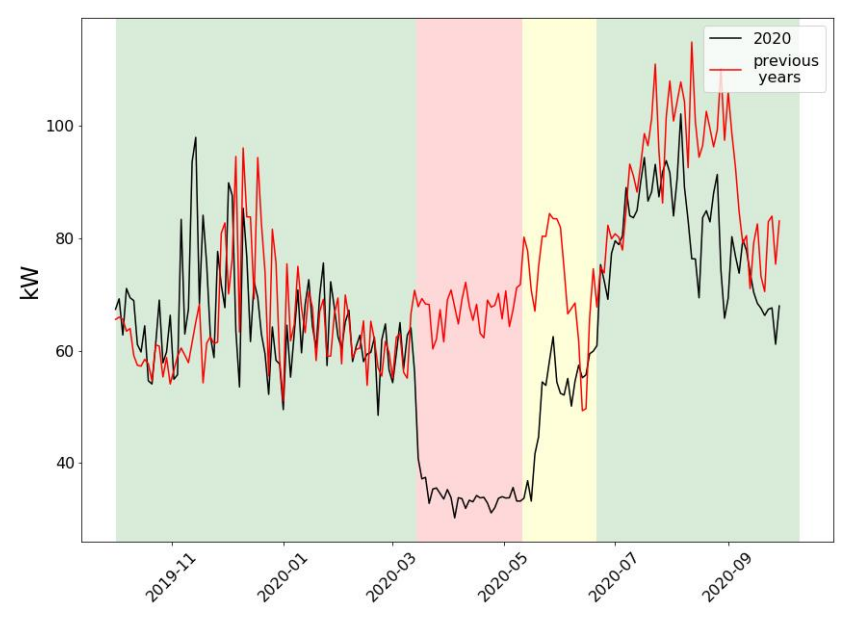

Fig 4. Aggregated consumption of non-residential customers from October 2019 to October 2020 compared with the consumption at the same period of the previous years.

\subsection{Energy consumption at Secondary Distribution Substation}

The impact of the COVID-19 pandemic can also be seen at secondary distribution substation level. 
As an example, two substations have been selected from the thirteen substations of Manzanilla. Specifically, the substations with higher (CT1) and lower percentage of non-residential customers (CT2) have been selected. Figure 5 shows the consumption at the substation with a higher percentage of non-residential customers (22\%). Figure 6 shows the consumption with the lower percentage of non-residential customers (4\%).

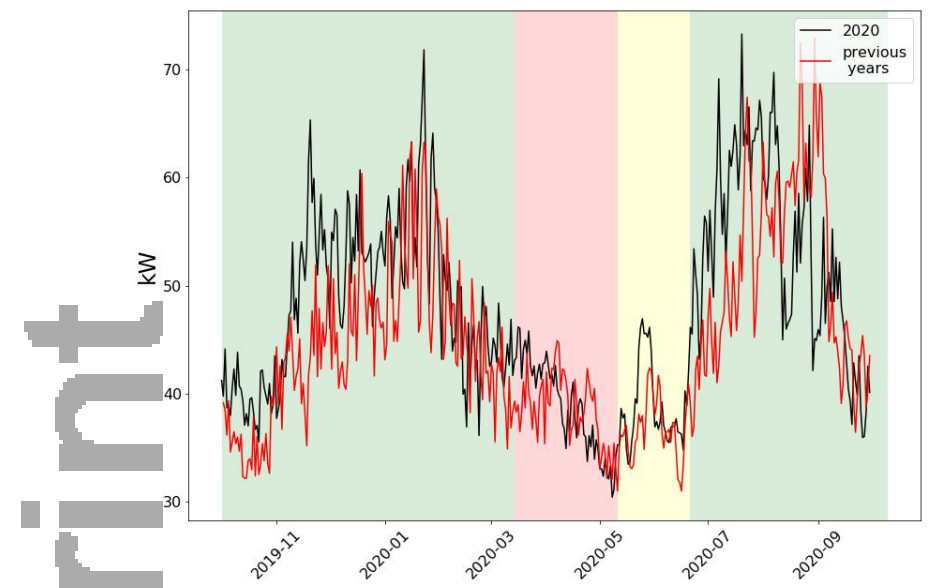

Fig 5. Consumption of CT1 from October 2019 to October 2020 compared with the consumption at the same period of the previous years.

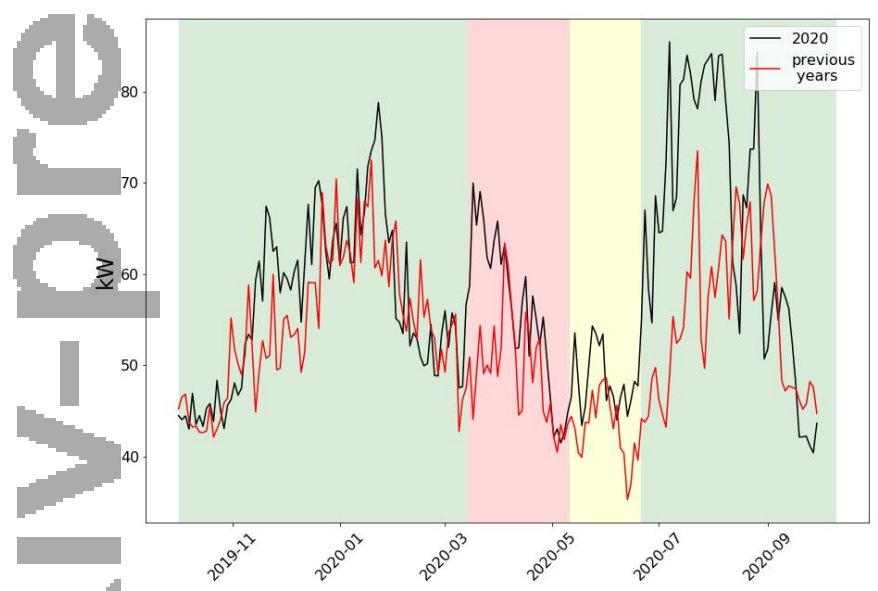

Fig 6. Consumption of CT2 from October 2019 to October 2020 compared with the consumption at the same period of the previous years.

CT2 has a similar behavior as residential customers. However, CT1 seems to have the same behavior that previous years. This is because the increment in consumption in residential loads is compensated by the reduction of non-residential loads.

\subsection{Behavior of specific non-residential customers}

Additionally, one of the advantages of the AMI, is that it can achieve a high level of disaggregation, allowing to obtain data at customer's supply point. In this sense, it is curious how non-residential customers have behaved differently during the pandemic. As an example, three customers are shown: CUST1, CUST2 and CUST3 in Figures 7,8 and 9, respectively.

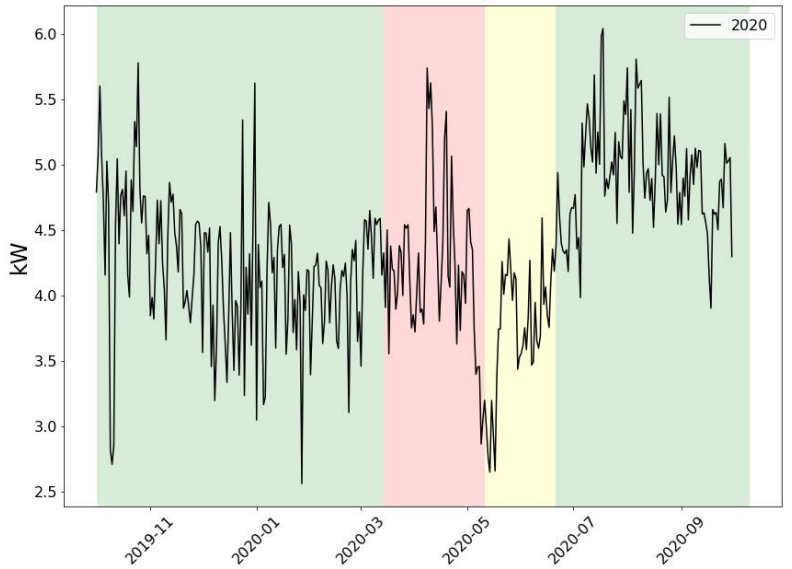

Fig 7. Consumption of CUST1 from October 2019 to October 2020.

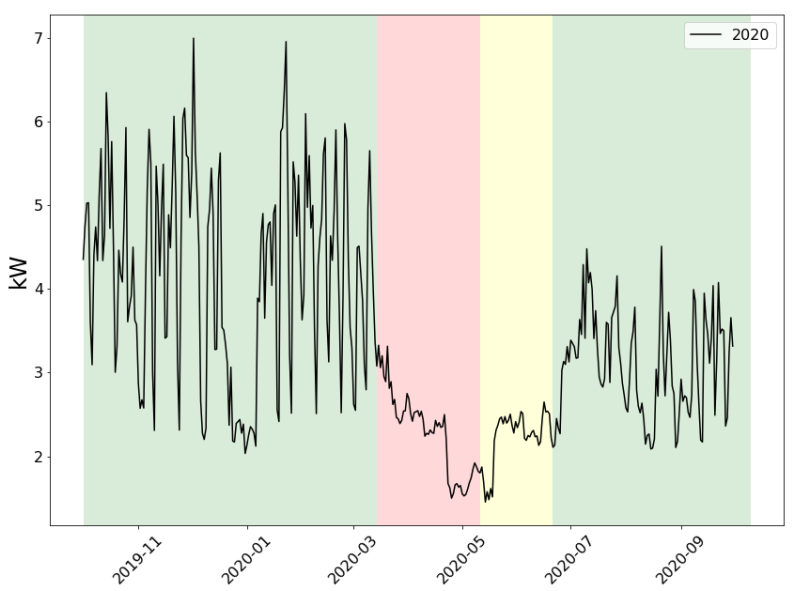

Fig 8. Consumption of CUST2 from October 2019 to October 2020.

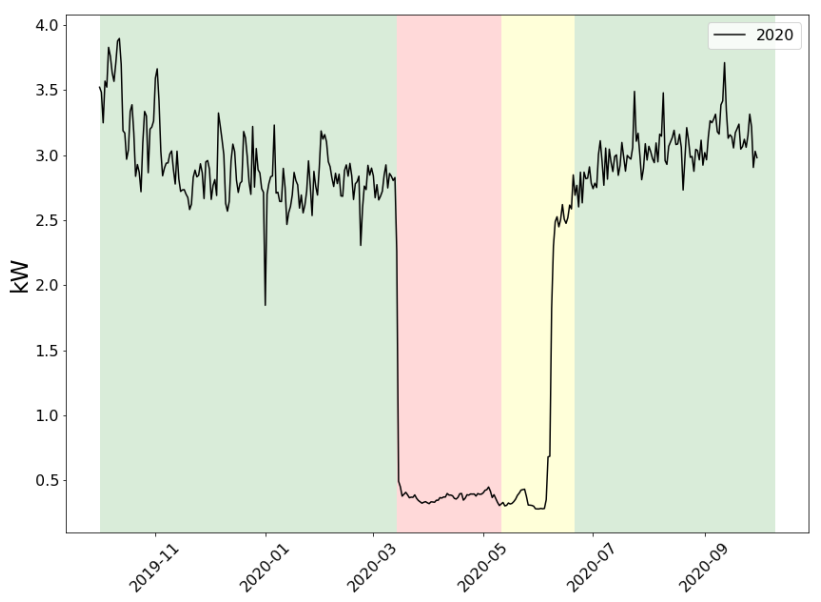

Fig 9. Consumption of CUST3 from October 2019 to October 2020. 
Three diferent consumption paterns can be observed from these non-residental customers during the COVID-19 restrictions. Firstly, CUST1 has (almost) maintained its consumption. Secondly, CUST2 has reduced considerately its consumption and have not recovered at a $100 \%$ after the supression of the restrictions. Finally, CUST3 has drastically reduced its consumption at the beginning of the lockdown but it has recovered to its previous level during the reopening period.

\section{CONCLUSIONS}

The COVID-19 pandemic has had a visible impact over the energy consumption. This impact can be clearly seen over the secondary distribution network.

This paper has studied how the restrictions imposed to control the spread of the virus have been reflected on the AMI systems of Manzanilla, Andalucía (Spain).

The results show how the effects over each type of customers are different, as can be observed in the comparison between residential and non-residential.

The analysis is exposed under the scope of lower levels: secondary distribution substations and individual cüstomers, showing various observed tendencies and different behaviors.

\section{ACKNOWLEDGEMENTS}

Authors wish to thank the Medina Garvey company for their willingness and support which have made possible the realization of this study. The work presented in this paper is founded by the "Ministerio de Ciencia, Innovación y Universidades", Government of Spain under the project "Bigdata Analitycs e Instrumentación Cyberfísica para Soporte de Operaciones de Distribución en la Smart Grid", number RTI2018-094917-B-I00. Sebastián García is also supported by this project. Moreover, Antonio Parejo is supported by the scholarship "Formación de Profesorado Universitario (FPU)", Grant Number FPU16/03522 from the "Ministerio de Educación y Formación Profesional", Government of Spain.

\section{REFERENCES}

[1] Wang Q, Lu M, Bai Z, Wang K. Coronavirus pandemic reduced China's $\mathrm{CO} 2$ emissions in shortterm, while stimulus packages may lead to emissions growth in medium- and long-term.
Applied

Energy

2020;278.

https://doi.org/10.1016/j.apenergy.2020.115735.

[2] Le Quéré $C$, Jackson RB, Jones MW, Smith AJP, Abernethy $S$, Andrew RM, et al. Temporary reduction in daily global $\mathrm{CO} 2$ emissions during the COVID-19 forced confinement. Nature Climate Change 2020;10:647-53. https://doi.org/10.1038/s41558-020-0797-x.

[3] Gillingham KT, Knittel CR, Li J, Ovaere M, Reguant $M$. The Short-run and Long-run Effects of Covid-19 on Energy and the Environment. Joule 2020;4:1337-41.

https://doi.org/10.1016/j.joule.2020.06.010.

[4] Abu-Rayash A, Dincer I. Analysis of the electricity demand trends amidst the COVID-19 coronavirus pandemic. Energy Research and Social Science 2020;68.

https://doi.org/10.1016/j.erss.2020.101682.

[5] Ghiani E, Galici M, Mureddu M, Pilo F. Impact on electricity consumption and market pricing of energy and ancillary services during pandemic of COVID-19 in Italy. Energies 2020;13. https://doi.org/10.3390/en13133357.

[6] Bahmanyar A, Estebsari A, Ernst D. The impact of different COVID-19 containment measures on electricity consumption in Europe. Energy Research \& Social Science 2020;68:101683. https://doi.org/10.1016/j.erss.2020.101683.

[7] Madurai Elavarasan R, Shafiullah G, Raju K, Mudgal V, Arif MT, Jamal T, et al. COVID-19: Impact analysis and recommendations for power sector operation. Applied Energy 2020;279:115739. https://doi.org/10.1016/j.apenergy.2020.115739.

[8] Yildiz B, Bilbao JI, Dore J, Sproul AB. Recent advances in the analysis of residential electricity consumption and applications of smart meter data. Applied Energy 2017;208:402-27. https://doi.org/10.1016/j.apenergy.2017.10.014.

[9] Moharm K. State of the art in big data applications in microgrid: A review. Advanced Engineering Informatics 2019;42:100945. https://doi.org/10.1016/j.aei.2019.100945.

[10] Wang $Y$, Chen $Q$, Hong T, Kang C. Review of Smart Meter Data Analytics: Applications, Methodologies, and Challenges. IEEE Transactions on Smart Grid 2019;10:3125-48. https://doi.org/10.1109/TSG.2018.2818167. 